Article

\title{
Organization of Laundry Facility Types and Energy Use in Owner-Occupied Multi-Family Buildings in Sweden
}

\section{Lena Borg * and Lovisa Högberg}

Department of Real Estate and Construction Management, KTH Royal Institute of Technology, Stockholm SE-100 44, Sweden; E-Mail: lovisa.hogberg@abe.kth.se

* Author to whom correspondence should be addressed; E-Mail: lena.borg@abe.kth.se; Tel.: +46-8-790-84-17.

Received: 25 April 2014; in revised form: 3 June 2014 / Accepted: 9 June 2014 /

Published: 16 June 2014

\begin{abstract}
The way in which we plan and produce buildings today will influence our energy consumption in the future. This paper explores how the types of laundry facilities provided in owner-occupied multi-family buildings in Sweden have changed since the 1990s and seeks to draw attention to how this may impact energy consumption for laundry. Three factors are analyzed that influence energy consumption: the number of laundry appliances, energy performance in laundry appliances and user demand for laundry. The results indicate that there has been a change in building practices, from the domination of communal laundry rooms towards in-unit laundry facilities. The findings imply that the changes in provision of laundry facilities increase the number of appliances but do not necessarily increase energy consumption during the usage phase depending on energy performance and user behavior. Thus, developers should consider laundry facility organization when designing multi-family buildings in order to optimize the use of space and resources, given user demand and building regulations. This paper is exploratory in nature and indicates a shift in building practices that up until now has been undocumented in a research context which in turn opens up for many new research questions related to resource use but also related to the economics of developers, housing firms and households.
\end{abstract}

Keywords: construction choice; new construction; energy consumption; energy efficiency; household laundry; multi-family buildings; building practice 


\section{Introduction}

The way in which we plan and produce buildings today will influence our energy consumption in the future. Indeed, developers have the potential to provide better-or worse - conditions in new construction for energy-efficient behavior, for example when installing appliances. Policy initiatives such as the EU directive on eco-design for energy-related products [1] will influence the energy performance of appliances, and consumer choice and behavior will ultimately play a decisive role in energy consumption. This study focuses on the intersection of technology and behavior to investigate how the organization of laundry facilities in new construction may impact energy consumption.

For decades, the standard for laundry facilities in Swedish multi-family buildings has been a communal laundry room in the same building or block, where households can book time to do their laundry, free of charge. This paper takes its starting point in a recent empirical observation for owner-occupied housing that indicates a change in new construction. Developers seem to be increasingly installing in-unit washers and driers in each unit, and sometimes providing concurrent access to communal laundry facilities [2]. Developers, it would seem, sacrifice the economies of scale derived from a centralized laundry system for consumer choice and convenience. If these observations reflect a systematic change in building practices, how may this way of organizing laundry facilities impact energy consumption?

Energy consumption for a specific area or function will depend on three factors: the number of energy consuming appliances, the energy use per occasion (time unit), and how much appliances are used [3]. To our knowledge, only a few research studies have been done on household washing behavior in general and related to different building practices in particular. Earlier studies have, however, suggested that from a life cycle or a system perspective, communal-based infrastructure such as a communal laundry room should be environmentally better than a product-based service like in-unit appliances [4]. One possibility is that a change to in-unit appliances provides residents with increased access and freedom of choice, which lowers the threshold to doing laundry and, therefore, increases energy consumption.

The aim of this paper is to shed light on some of the recent developments in the construction of multi-family housing, and to assess how it may impact total energy use in multi-family houses. To fulfill the aims, the first research question to be answered was: How have developers designed laundry facilities in new multi-family buildings for tenant-owner associations in the past, and how are these facilities designed today? Historically, communal laundry rooms have been the norm, but our field observations indicated that in-unit appliances are becoming more common and our task was to research the extent of the change.

We then explored how energy consumption used for laundry might change if building practices change. What impact might the new type of laundry facilities have on energy use in a building? A different arrangement might result in higher energy consumption for doing laundry if the number of appliances increases, if the energy performance of in-unit appliances is worse than that of communal appliances, and if tenants increase their demand for laundry.

Our approach is to document the building practices of the latest thirty years and not an attempt to explain why the changes have occurred. Furthermore, we only look at new construction for housing cooperatives in Sweden. 
The organization of this paper is as follows. In Section 2, we provide a brief background of laundry facilities and household energy consumption in Sweden. We also introduce the analytical framework by describing the current situation for the three energy-driving factors. Section 3 is the methods section where we explain how the collection of data and the calculations were carried out. In Section 4, we present the empirical results from the documentation of building practices. Possible implications of the empirical findings are analyzed in Section 5. The results are discussed in Section 6 and some concluding remarks can be found in Section 7.

\section{Background and Analytical Framework}

\subsection{The Communal Laundry Room}

The communal laundry room is a typical Swedish concept, springing from the political ideal of the equal right to stay clean [5]. During the interwar years, various political and social movements were making their voices heard in an effort to reform the housing sector in Sweden and improve living standards and hygiene in the cities. Pioneering efforts were carried by the Swedish Tenant Owners' Association (HSB), a housing firm, which was the first to build communal laundry rooms in multi-family buildings already in the early 1920s. A widespread breakthrough promoted by municipal housing firms during the post-war era helped make the communal laundry room standard in Swedish multi-family buildings. In the 1940s, communal laundry rooms were routinely planned in new developments and became a norm in the 1950 s. Soon, $80 \%$ of the households in multi-family buildings had access to communal laundry rooms which increased to $90 \%$ in the $1960 \mathrm{~s}$ and in the $1970 \mathrm{~s}$ had grown to the vast majority of households $[5,6]$. Today the approximately 30,000 communal laundry rooms in Swedish owner-occupied and rental multi-family buildings are equipped with an estimated 200,000 washing machines. In addition, there are an estimated 800,000 in-unit washing machines in multi-family buildings and approximately 270,000 common and in-unit tumble dryers [7-9].

\subsection{Owner-Occupied Multi-Family Housing and Laundry Facilities}

Housing cooperatives, a form of tenant-owner tenure, account for $38 \%$ of the Swedish multi-family housing stock or approximately 2,382,000 dwellings. In 2011, 8413 units in housing cooperatives were completed in Sweden, which was $51 \%$ of the total construction of multi-family buildings [10]. Housing cooperative buildings are formally owned by a tenant-owner association (TOA), which gives all the co-owners some influence over building-related issues. The TOA board most often acts on behalf of its members; the exact issues and their extent depend on the TOA statutes.

According to the Swedish minimum building requirements (BBR), multi-family housing needs to offer a communal laundry in or close to the building, independent of tenure form. Historically, the laundry rooms have been placed in inaccessible spaces in the building's basement, but because of accessibility regulations as well as safety and well-being, it is becoming more common to place the laundry rooms on the ground level, with windows [5]. If there is no communal laundry room, the BBR state that every unit should have a specified and defined space for laundry machines [11]. For owner-occupied housing, the communal laundry room provision is an internal matter for the TOA. There are not specific requirements for these communal spaces, but industry recommendations call for 
at least two washing machines and one dryer and/or drying cabinet for every 35 units, if possible [12]. This allows each household at least weekly access to a three-hour time slot (laundry hours are usually restricted due to the noise), corresponding to approximately six laundry cycles per week.

Different washers and dryers have different specifications and there may be a tradeoff between their different features, such as size, cycle length, energy efficiency, noise level, operation costs, maintenance costs, and life length. For example, communal laundry rooms are typically equipped with larger and more durable appliances ("professional" washing machines and tumble dryers) to endure frequent use. The wash cycle is usually shorter than that of in-unit appliances to allow residents to maximize the limited laundry time available. In-unit appliances are usually slower and quieter than professional appliances $[5,7,8]$.

Traditionally, the charge for using the communal laundry rooms has been included in the TOA fee. The fee covers operation and maintenance of the facilities and the users pay for laundry detergent, etc. When technically feasible and allowed by the TOA, it has been possible for tenant-owners to install in-unit washing machines on their own initiative. The operation, maintenance, and replacement of in-unit appliances are the responsibility of the tenant-owner.

\subsection{Determinants of Laundry-Specific Energy Consumption}

The variation between households in energy use for laundry may largely depend on household composition and other socio-economic and cultural characteristics [13-16]. The average Swedish multi-family building unit consumes around $3000 \mathrm{kWh}$ of electricity per year. Studies of household energy consumption indicate that $7 \%, 210 \mathrm{kWh}$ per year, of household electricity in multi-family units is used for washing and drying laundry $[13,14]$.

Household energy use in general, and electricity use for doing laundry in particular depends on three factors: (i) the number of appliances; (ii) the energy use per occasion/time unit (energy performance); and (iii) how the residents use the appliances. The first two factors are technical and the third is behavioral. Below is an attempt to describe the current situation.

(i) Statistics Sweden [17] reports that in 2006-2007, almost 75\% of the population 16-84 years of age had access to a washing machine of their own. The corresponding number in housing cooperatives (usually multi-family) was $57 \%$. One third of the households living in multi-family buildings (rental) stated that they had in-unit washing machines. Tumble dryers, on the other hand, were rare among households in multi-family buildings [13]. In a survey carried out by Zimmerman [14], 200 Swedish households living in multi-family buildings stated that they possessed on average 0.51 washing machines and 0.15 tumble dryers. Depending on household type (singles, couples, and families, aged 26-64 or +64 years) possession varied between $0.39-0.63$ washing machines and $0.1-0.21$ tumble dryers.

(ii) Technological advances have increased the energy efficiency of washers and dryers. Between 1993 and 2013, energy consumption per cycle in new washing appliances has been reduced by more than 50\%. Energy efficiency in tumble dryers improved by 12\% between 1995 and 2005 . One driving factor has been the energy labeling of energy-consuming appliances, which requires manufacturers to display energy performances on individual appliances to guide consumers in making energy efficient choices $[1,18,19]$. The labeling has been successful and 
the variation in energy performance in most modern appliances today is so small that energy efficiency has become a "secondary property" relative to other features of the appliances.

(iii) As technology and social norms have changed, laundering has increased in the past century for behavioral reasons. An increased individualization and higher demands for efficiency have enabled the transition from past processes of washing under difficult conditions to disinfect the laundry to today's laundering, which oftentimes is done to feel "fresh", regardless of actual "dirt". This means our laundry habits have changed from washing infrequently and for long periods to washing more often but for short periods $[5,13,20]$. Swedish households have more than doubled their laundry loads between the 1930s and the 1980s, and US households have tripled their loads since the 1950's [18,19].

In a Swedish study from 2003, using survey data for 600 Swedish households showed that approximately $52 \%$ of the households studied used their washing machine 4-6 times a week [13]. In another study, Zimmerman [14] monitored and measured the laundry patterns of 400 Swedish households from 2005 to 2007 and estimated that Swedish households living in multi-family buildings wash on average 2.9 cycles per week. Internationally, similar washing patterns have been observed. A German consumer study showed that households washed 2-6 cycles per week and other EU and US data is within this range, with approximately 5 cycles per week [21-23].

For tumble dryers, a study of 250 households in Poland, France and the UK showed that the average use was 2.3 drying cycles per week in the summer and 3.6 cycles in the winter [24]. In the US, the Department of Energy estimates that the average number of cycles per week is 5.5. This figure might seem high, which may be because washing loads are split into two or more clothes dryer loads [25].

As mentioned previously, variation between households in demand for laundry is influenced by various factors, such as dwelling size, age, household income and tenure [13,14,17,23,26-28]. As Davis [16] has showed, demand for laundering is endogenous with respect to which appliances households buy. Households that put a relatively high value on the household service laundry will buy more efficient appliances, which is not to be confused (altogether) with more efficient appliances yielding higher user intensity. Changes in circumstances, such as a new organization of laundry facilities, may impact the marginal (alternative) cost and the marginal utility residents experience from doing laundry, the extent of each impact will ultimately determine changes in laundry demand.

\section{Method and Data}

\subsection{Empirical Study}

In the empirical part of this study, we focus on the connection of building practices and factor (i), the number of appliances. Data was collected in two steps. First, an on-site survey was undertaken to document building practices in Swedish multi-family buildings in different periods. The study objects were multi-family buildings owned by housing cooperatives in Stockholm central suburban areas. Buildings with units for sale were surveyed in November and December 2012 and in March 2013. A checklist was used. A total of 31 buildings were surveyed, 9 of which were built in 1990 to 1991, 
9 were built between 2000 and 2002, and 13 buildings were built between 2009 and 2011. Data was collected for 72 features in four categories: the building, the unit, the kitchen, and the bathroom. The presence of a communal laundry room was one of the 15 features looked for in the building category. An originally installed washing machine, tumble dryer or a combined washer/dryer were three of the features looked for in the bathroom category. For more information about the data and data collection, see Borg and Song [2].

Second, to document current practices the historical data were supplemented with the latest information from the six biggest Swedish developers. This included ongoing construction projects that had been initiated no earlier than 2012. Information about laundry facilities available in multi-family buildings currently under construction was collected through the firms' web pages. Data was collected from Stockholm and the other four largest cities in Sweden (Gothenburg, Malmö, Linköping, and Uppsala) to ensure that a (possible) observed trend wouldn't be just regional, such as for Stockholm central suburban area. In total, information from 136 multi-family projects was collected. In 11 cases there were difficulties in collecting information through the web pages so email requests for information were sent to the project managers, who promptly answered.

\subsection{Analysis}

To analyze the possible impact the observed change might have on energy consumption, we revisit factor (ii) and (iii) in a numerical example to illustrate how the organization of laundry facilities may influence energy consumption. The numerical example compares three type buildings which reflect three ways of organizing laundry facilities. To facilitate comparison, the type buildings are all assumed to be new construction and each of the model buildings has 35 units.

Our base case, building 1, reflects the traditional way of organization and has one communal laundry room equipped with two washing machines and one tumble dryer. Type building 2 is a reflection of the new laundry organization with only in-unit washing appliances, one washing machine and one tumble dryer per unit, a total of 35 washing machines and 35 dryers for the building. Type building 3 reflects the transition period and is designed with both a communal laundry room and in-unit appliances. Type building 3 thus has $2+35$ washing machines and $1+35$ tumble dryers.

To get an indication of energy performance in our example, we used the European Union consumer information website Topten [29], which reflected the best available technology choice available on the market. Assuming the best available technology is chosen, the difference in energy performance between communal laundry appliances and in-unit appliances will depend on the different standard in each category. Topten mainly ranks household appliances and had no category for (semi)professional washing machines. Information about (semi)professional appliances was taken from the Swedish Energy Agency and their testing lab [7]. To facilitate comparison per washing cycle, we chose examples of similar size even though communal appliances on average probably will have a higher capacity.

Using the three type buildings and the chosen characteristics, we calculated the average energy consumption for laundry over the course of a year. The results for the in-unit case and the in-unit plus communal laundry room case, respectively, were compared to the traditional communal laundry room case. 
Note that we only consider the usage phase and not the energy use before and after the active life cycle of the appliances. Considering a life cycle perspective, the energy savings from replacing old appliances with more efficient ones should be contrasted to the energy needed to manufacture the new appliances. However, the energy consumed by an appliance during the usage stage is $80 \%$ of its life cycle energy use, thus far greater than that used in other stages [4,30]. It is also important to consider other energy needs, for example to light up and heat the facilities. This, however, is beyond the scope of this paper.

\section{Empirical Results}

\section{Changes in Construction Practices}

Over the course of the studied period, there have been clear changes in construction practices (Table 1). Our on-site observations revealed that buildings constructed from 1988 to 1991 follow the practice of having a communal laundry room. The buildings had not installed in-unit washing machines or tumble dryers as standard items (Table 1, upper panel).

Table 1. Laundry facility organization from late 1980 s to 2010 s and 2012 onwards.

\begin{tabular}{|c|c|c|c|c|c|}
\hline \multicolumn{6}{|c|}{ Laundry Facility Organization from Late 1980 s to $2010 \mathrm{~s}$} \\
\hline & Construction Year & $\mathbf{N}$ & Only Common (n) & Only in-unit (n) & Common + in-unit (n) \\
\hline On-site & 1988-1991 & 9 & $100 \%(9)$ & $0 \%$ & $0 \%$ \\
\hline observations, & $2000-2002$ & 9 & $0 \%$ & $11 \%(1)$ & $89 \%(8)$ \\
\hline Stockholm & 2009-2011 & 13 & $0 \%$ & $23 \%(3)$ & $77 \%(10)$ \\
\hline \multicolumn{6}{|c|}{ Laundry Facility Organization in New Construction Projects, 2012 onwards } \\
\hline & Local Market & $\mathbf{N}$ & Only Common (n) & Only in-unit (n) & Common + in-unit (n) \\
\hline \multirow{6}{*}{$\begin{array}{c}\text { Developer } \\
\text { observations }\end{array}$} & Stockholm & 76 & $0 \%$ & $78 \%(59)$ & $22 \%(17)$ \\
\hline & Gothenburg & 25 & $0 \%$ & $84 \%(21)$ & $16 \%(4)$ \\
\hline & Malmö & 15 & $0 \%$ & $80 \%(12)$ & $20 \%(3)$ \\
\hline & Linköping & 4 & $0 \%$ & $100 \%(4)$ & $0 \%$ \\
\hline & Uppsala & 16 & $0 \%$ & $75 \%(12)$ & $25 \%(4)$ \\
\hline & Total & 136 & $0 \%$ & $79 \%(108)$ & $21 \%(28)$ \\
\hline
\end{tabular}

After 1991, a major shift in laundry facilities can be observed among multi-family buildings owned by housing cooperatives. Developers rapidly shifted from designing buildings with communal laundry rooms towards installing in-unit facilities. The survey of buildings that were constructed around 2000, showed that all the units were designed with in-unit washing appliances. However, supplementary communal laundry rooms were available in most of the buildings. The overall design of multi-family buildings remained unmodified during the first decade of the 21th century. Until around 2010, buildings were designed with in-unit appliances, sometimes in combination with communal laundry rooms (Table 1, upper panel).

The information on projects under construction during 2012 and onwards reveals that the design of new buildings has shifted rapidly (Table 1, lower panel), with a clear pattern towards the use of in-unit appliances. A second trend, almost as striking, is the move away from communal laundry rooms. On-site field studies have not been done for the other cities. However, there were no indications from 
the websites or emails from project managers that this was a regional trend concentrated to Stockholm (Table 2, lower panel).

Table 2. Model buildings and key characteristics.

\begin{tabular}{|c|c|c|c|}
\hline Technical data & Building 1 & Building 2 & Building 3 \\
\hline Washing appliances & $\begin{array}{l}2 \text { communal } \\
\text { washing machines }^{\text {a }}\end{array}$ & $\begin{array}{l}35 \text { in-unit washing } \\
\text { machines }{ }^{b}\end{array}$ & $\begin{array}{l}2 \text { communal washing } \\
\text { machines }{ }^{\text {a }} \text {, } \\
35 \text { in-unit washing } \\
\text { machines }{ }^{b}\end{array}$ \\
\hline $\begin{array}{l}\text { Energy use per washing } \\
\text { cycle, } \mathrm{kWh} \text { (at half load } \\
40 / 60 \text { degrees) }\end{array}$ & $0.41 / 0.65$ & $0.55 / 0.60$ & \\
\hline Drying appliances & 1 communal dryer $^{\mathrm{c}}$ & 35 in-unit dryers ${ }^{d}$ & $\begin{array}{l}1 \text { communal dryer }{ }^{c} \text {, } \\
35 \text { in-unit dryers }{ }^{d}\end{array}$ \\
\hline $\begin{array}{l}\text { Energy use per drying } \\
\text { cycle, } \mathrm{kWh}\end{array}$ & 1.61 & 1.08 & \\
\hline Laundering availability & $\begin{array}{l}\text { Five daily laundry slots } 7 \mathrm{am}-10 \mathrm{pm} \\
\text { (on average one three-hour slot per } \\
\text { household per week) }\end{array}$ & Unlimited $24 \mathrm{~h}$ & Unlimited $24 \mathrm{~h}$ \\
\hline Behavioral data & Building 1 & Building 2 & Building 3 \\
\hline Charge & Included in monthly fee & Electricity & Electricity \\
\hline $\begin{array}{l}\text { Washing cycles per day } \\
\text { per building }\end{array}$ & 25 & 25 & 45 \\
\hline $\begin{array}{l}\text { Drying cycles per day } \\
\text { per building }\end{array}$ & 15 & 15 & 15 \\
\hline
\end{tabular}

${ }^{a}$ Electrolux W465H, $6.5 \mathrm{~kg}$ washing load [7]; ${ }^{\mathrm{b}}$ Adorina SL V-Zug, $7 \mathrm{~kg}$ [29]; ${ }^{\mathrm{c}}$ Bauknecht TRW5070,

$7 \mathrm{~kg}$ washing load [29]; ${ }^{\mathrm{d}}$ Siemens WT48Y7W1 $8 \mathrm{~kg}$ washing load [29].

\section{Implications of Changes in Construction Practices}

\subsection{Factor (i) Change in Number of Appliances due to Changes in Building Practices}

Clearly, the two newer ways of organizing laundry facilities in buildings 2 and 3 have an impact on factor (i) and increase the total number of appliances. If all of the in-unit appliances would be utilized to their maximum, the total number of hours of washing would be much higher in buildings 2 and 3 than in building 1 . Moreover, in a communal laundry room there is also the possibility to restrict households' access to the facilities to certain hours.

\subsection{Factor (ii) Differences in Energy Performance due to Changes in Building Practices}

For a given laundry session, energy performance may vary between the appliances that are used communally and privately. Studies have shown that communal appliances are often more modern because of a higher replacement rate [4,13]. Different industry standards and user demands may require different energy performance. In-unit appliances as well as "semi-professional" appliances for communal use are often smaller and better adapted to the smaller household size of today. This means 
that each cycle consumes less energy than that of professional appliances, but also that they are less energy efficient per kilogram of laundry (assuming similar energy standards and washing at full load).

On the other hand, there may be differences in what appliances are installed depending on who is responsible for operation and maintenance. Appliances in rental housing have, for example, been found less efficient than appliances in owner-occupied housing [31,32]. A similar principal-agent problem arises in our example if developers choose less efficient in-unit appliances that are cheaper upfront because the TOA or the tenant-owners pay for operations.

We have no information about the appliance choice developers make, but we do know that energy performance of new appliances in general is high today. We also know that the difference in energy performance between appliances might be the result of the concurrent demands that appliances need to fulfill, such as noise levels or washing cycle length. This implies that the major difference is expected to be between communal and in-unit appliances, rather than within the various communal or the various in-unit appliances.

Table 2 shows the energy performance of in-unit and communal appliances of similar capacity based on the best available technology. The communal washing machines use less energy than the in-unit appliances per 40 degree wash, but the reverse is the case per 60 degree wash. Communal tumble dryers use almost 50\% more energy than in-unit tumble dryers. Total energy consumption will thus depend on how the appliances are used.

In our numerical example, we assume that every household in building 1 uses its weekly time slot and washes five cycles a week, which yields 25 wash cycles per day for the building. We assume they use tumble dryers three times per week, resulting in 15 drying cycles per day for the building. These laundry patterns are within the range of previous studies [13,14,21,23,24].

For building 2, we hold demand for laundry constant and assume that households with in-unit appliances launder with the same frequency. For building 3, we assumed the same common laundry pattern as for building 1 and added half of the laundering from building 2. This corresponds to a situation where households continue to do laundry in the communal facilities and throw in the occasional batch of laundry to have it freshened up as indicated in Karlsson and Widén [3].

Table 3 shows the resulting annual energy consumption for the three type buildings. Looking at washing separately, in-unit appliances are more energy consuming which results in higher energy consumption in building 2 than in building 1. For drying, the pattern is the opposite; energy consumption for drying is higher in building 1 than in building 2. Taken together, with the same demand for laundry, the total effect is that building 1 with communal laundry room uses more energy than building 2 with in-unit appliances. The double access in building 3 of course yields much higher energy consumption than building 1 , since we simply added washing in this scenario.

The difference between building 1 and 2 in energy consumption results from the technological differences in appliances and is an indirect result of the changed building practices. The difference between building 1 and 3 results from technological differences and is reinforced by a difference in behavior, an increased demand for laundry. 
Table 3. Annual energy consumption, kWh (difference compared to base case "Building 1").

\begin{tabular}{cccc}
\hline $\begin{array}{c}\text { Appliance } \\
\text { Type }\end{array}$ & $\begin{array}{c}\text { Building 1: } \\
\text { Communal (Base Case) }\end{array}$ & $\begin{array}{c}\text { Building 2: } \\
\text { In-unit }\end{array}$ & $\begin{array}{c}\text { Building 3: } \\
\text { Communal + In-unit }\end{array}$ \\
\hline Washing & 4835 & $5245(+8.5 \%)$ & $7460(+54 \%)$ \\
Drying & 8815 & $5885(-33 \%)$ & $8815(+/-0 \%)$ \\
Total & 13,650 & $11,130(-18.5 \%)$ & $16,275(+19 \%)$ \\
\hline
\end{tabular}

(1) The calculations were made by multiplying the assumed number of daily washing and drying cycles with the energy consumption per washing/drying cycle (using the 40 degree figure for half of the wash cycles and the 60 degree figure for the other half) and then multiplying by 365 to get the annual figure; (2) Dividing the total energy consumption by average dwelling size in new construction $\left(99.1 \mathrm{~m}^{2}\right.$, in 2009) [33] yields an Energy Use Intensity (EUI) of $138 \mathrm{kWh} / \mathrm{m}^{2} /$ year, $112 \mathrm{kWh} / \mathrm{m}^{2} /$ year and $164 \mathrm{kWh} / \mathrm{m}^{2} /$ year respectively.

\subsection{Factor (iii) Differences in Demand for Laundry due to Changes in Building Practices}

Thus far we have seen that a change in building practices from communal laundry room to in-unit appliances leads to a higher number of appliances. One consequence of this is that communal appliances are replaced by in-unit appliances. The appliances used in either type of facility will have different energy standards, given best available technology, which then implies a change in total energy consumption for laundry. Based on the differences in energy consumption in Table 3 above, we altered the in-data for laundry behavior and looked for the tipping points that would be necessary to make the two cases (only communal laundry room versus only in-unit appliances) to break even in energy consumption. In addition to identifying the tipping points, we contrasted with a change in demand in the opposite direction.

The direction of a change in demand for laundry resulting from a change in building practices is not obvious. If the tenant-owner is directly responsible for all laundry-related costs, according to economic theory, he or she should launder less than when costs are shared communally. On the other hand, to higher income households (who are likely to live in cooperative housing units), the value of time is higher and the direct energy cost of laundering might be marginal. Households with in-unit appliances are closer to the appliances and basically have no time restrictions on their laundering. This makes it more convenient to do laundry, in which case they might do it more often to "feel fresh". On the other hand, some households might prefer to use the communal laundry room and do all their laundry at once.

We now compare only building 1 and 2, and look at the possible impact of changes in laundry demand from different organization. Table 4 shows the change in energy consumption resulting from a change in demand for laundry. Scenarios a-b illustrates an increase in demand with in-unit appliances and scenarios c-d illustrates a decrease in demand with in-unit appliances.

The 35 households with in-unit appliances would have to increase the total washing in the building from 25 to 37 times per day, or do on average 7.4 (instead of 5) wash cycles per week per household (keeping tumble drying frequency constant) to consume as much energy for laundry as building 1 does (Table 4, scenario a). If we, instead, keep washing constant and change only tumble drying in the in-unit appliance case, the 35 households would have to run a total of 22 drying cycles per day (4.4 drying cycles per week per household) to consume as much energy as building 1 does (Table 4, scenario b). 
Table 4. Tipping points in energy consumption due to changes in laundry demand.

\begin{tabular}{ccc}
\hline $\begin{array}{c}\text { Alternative scenario for building 2: } \\
\text { Assumed changes in laundering behavior }\end{array}$ & $\begin{array}{c}\text { Energy consumption, } \\
\mathbf{k W h} / \mathbf{y} \text { ear } \\
\text { Building 1: } \\
\text { Only communal }\end{array}$ & $\begin{array}{c}\text { Energy consumption, } \\
\mathbf{k W h} / \mathbf{y} \text { ear } \\
\text { Building 2: } \\
\text { In-unit }\end{array}$ \\
\hline $\begin{array}{c}\text { Base case consumption } \\
13,650(4835+8815)\end{array}$ & $11,130(5245+5885)$ \\
\hline $\begin{array}{c}\text { Increase in-unit washing to 37, } \\
\text { all else equal. }\end{array}$ & $13,650(7765+5885)$ \\
\hline $\begin{array}{c}\text { Increase in-unit drying to 22, } \\
\text { all else equal. }\end{array}$ & $13,875(5245+8630)$ \\
\hline $\begin{array}{c}\text { Decrease in-unit washing to 20, } \\
\text { all else equal. }\end{array}$ & $10,085(4200+5885)$ \\
\hline $\begin{array}{c}\text { Decrease in-unit drying to 10, } \\
\text { all else equal. }\end{array}$ & $9170(5245+3925)$ \\
\hline
\end{tabular}

If in-unit appliances lead to households reducing their demand for laundry, the energy consumption of building 2 would naturally be further reduced. In the first example, drying was kept constant at 15 cycles and washing was reduced to 20 cycles per day, corresponding to 4 cycles per week per household (scenario c). In scenario d, washing was kept constant while use of in-unit tumble dryers in building 2 was assumed to drop to a total of 10 cycles per day, or 2 cycles per week per household. In both of these cases, laundering in building 2 required less energy than laundering in building $1 \mathrm{did}$.

\section{Discussion}

\subsection{Changes in Building Practices and the Number of Appliances}

When developers install in-unit appliances, whether to replace or supplement the communal laundry room, the total number of appliances for a given multi-family building will increase. Differences in wear and tear may cause the appliances to wear out at different rates and hence to need replacing at different intervals. To the extent that less frequent use of in-unit appliances give them a longer life cycle, the total number of common appliances might increase compared to the number of in-unit appliances over an extended time period. A shorter replacement interval, however, should not be enough to outweigh the initially higher number of in-unit appliances over a specific period of time and we expect an increase in the total number of appliances.

The shift in construction practices towards including more in-unit appliances have occurred without any formal requirement such as a new regulation. One explanation might be that there is a customer-driven demand for individual laundry facilities in the units. Studies have shown that the communal laundry room is a common place for conflict and that residents would prefer to avoid this [5,34]. In addition, other regulations have changed with implications for design and planning; building regulations now require better accessibility which has led to bigger bathrooms [35]. The enhanced bathroom size in combination with increased customer demand for in-unit appliances allows developers to make use of otherwise unused space. At just a small additional cost, they can meet the customers' demands and enhance customer utility but also, it is assumed, demand a price premium on the (new market) selling price. 
Developers are also increasingly abandoning the communal laundry room. A plausible reason is the alternative cost — by doing so they are able to utilize the then available space to increase the size of the units or even build an additional unit, which may generate higher revenue. To the extent that they still build communal laundry rooms, this is more often than before placed on the ground floor. This implies that there will be a tradeoff between lower costs for underground construction and an alternative use for ground floor space. For this reason, we expect the communal laundry rooms to gradually disappear. Another possible explanation might be that energy consumption in buildings is high on the agenda these days. Mandatory energy performance certificates and other building performance labelling schemes for sustainability aspects signal the importance of low energy consumption. Electricity use for the communal laundry room is included in the building energy use and energy use for in-unit appliances is included in household energy use, in the official statistics as well as well as in how energy is charged. Organizationally moving laundry specific energy consumption to the households thus will make energy performance of the building look better even if total energy use would be the same [36]. Again, our examples show that energy consumption doesn't necessarily increase, but if we want to reduce total energy consumption we need to holistically consider what impact this kind of changes will have.

\subsection{Changes in Building Practices and Energy Performance}

As we have seen, there are differences in energy performance between modern communal and modern in-unit appliances. As long as this difference remains, even if developers aim for the best performance in appliances there will be a difference in total laundry-specific energy consumption between the two cases, provided demand for laundry stays unchanged. In our example, this was to the advantage of in-unit appliances when summarized, but differed between washers and dryers.

A change in building practices may also result in an agency problem. If the communal laundry rooms disappear, there is a risk that developers will install cheaper and less energy-efficient in-unit appliances to maximize profits. Tenant-owners will be left with the operation and maintenance bill over the working life of the energy consuming appliances. However, observations from our new construction projects indicate that there is remedy to this problem; developers often offer tenant-owners a choice between appliances with different energy performance. This ensures that the person who will be responsible for future operations and maintenance also has the option of paying more upfront to minimize life cycle energy consumption and costs.

\subsection{Changes in Building Practices and Household Demand for Laundry}

Our calculations show that installation of in-unit appliances could actually lead to a reduction of laundry-specific energy consumption in multi-family housing. However, a reduction in building energy consumption may be outweighed by an increase in household energy consumption if households with in-unit laundry facilities also increase laundering frequency. As shown in the tipping point analysis, only 2.4 more wash cycles per week and household were needed for in-unit laundering to exceed the energy consumption of communal laundering. Perhaps this possible rebound effect is easily achieved when laundry facilities are more readily available. On the other hand, a shift to in-unit appliances also implies a relocation of laundry specific operation and maintenance costs from the TOA 
collective to the household, which would send more correct (price) signals and create incentives for energy saving behavior. Which of these incentive effects remains stronger is an empirical question. According to Davis [16], there is only a small rebound effect of having more efficient appliances (and thus a lower marginal cost), mainly because households that put a high value on laundering weigh this into the appliance purchasing decision. In our case, when households have less influence over appliance choice in the communal laundry room case this aspect might be more relevant.

When thinking about how a change in laundry facilities organization impacts laundering behavior, we need to consider two factors: utility and cost. If households find it inconvenient to do laundry in a communal laundry room, for example because of conflicts, distance, or time restrictions, their utility will increase with the increased freedom and convenience of having in-unit appliances. On the other hand, leaving households with no other choice than to launder in their own unit could imply a different type of inconvenience. For example, if households dislike having their washing machine running frequently (instead of being able to use parallel washing machines, possibly with bigger capacity), or if they dislike being responsible for operation and maintenance, this may lower the utility of households with (only) in-unit appliances.

Changes in the marginal (alternative) costs may occur for partly the same reasons. Proximity and easy access to laundry facilities may lead to a higher frequency of washing among residents if the time cost is lowered. The changed social norms about "feeling fresh" and the larger variety in washable fabrics that need separate treatment are examples of factors that would lead us to assume an increase in laundering, if they before were constrained by restricted access to the communal laundry facilities. An indication of this tendency was reported in Karlsson and Widén [3]. Furthermore, residents may overuse or be careless with communal appliances if they know they only have to pay for a fraction of the operation and replacement cost, compared to having to pay for an in-unit replacement themselves. Conversely, the higher costs for residents when being directly responsible for the operation and maintenance of their in-unit appliances may contribute to a reduction in washing.

Ultimately, we have to compare the households' marginal utility of one extra washing or drying cycle to the marginal cost of that extra cycle after a change in laundry facility organization to be able to evaluate total impact. Tumble drying serves as an example of how this could play out. Previous studies have shown that households that have in-unit tumble dryers use them less frequently because of the high amount of energy they consume [3]. The difference in energy consumption between communal tumble dryers and in-unit tumble dryers is relatively large. If we assume that households run their tumble dryers the same number of cycles, the technological difference results in lower energy consumption for the in-unit case. Thus, the high energy consumption and increase in directly related households cost may lead to a decrease in demand despite the fact that tumble drying should give households with in-unit appliances a higher utility, e.g., thanks to avoiding having to clutter the home with drying laundry,. If the above is a realistic description of reality, price signals are expected to reinforce the energy-saving impact of the technological difference for households with in-unit appliances instead of communal laundry rooms. 


\section{Conclusions and Future Research}

In this paper, we have studied how developers' building practices have changed in the case of laundry facility provision. Our study shows that there has been a shift in practices; in new construction for tenant-owner associations, the communal laundry rooms have largely been replaced by in-unit appliances. Judging from current new construction projects, this trend will continue and the communal laundry room will become history. We can only speculate about the motivation behind this shift, but, given our observations, we can consider the various impacts the change might have on energy consumption.

Our numerical example shows that laundry-specific energy consumption does not necessarily increase during the usage phase from the shift to having only in-unit appliances. The somewhat unexpected reduction in energy consumption is driven by technological factors; assuming identical behavior and given the lower energy consumption of in-unit appliances, the total energy consumption will be lower. This result is only valid as long as the differences in energy performance between communal and in-unit appliances remain.

Lower energy consumption resulting from a shift to in-unit appliances may be reinforced by changes in behavior depending on how households value the utility of experiencing the full benefits of easy access to the appliances as well as the full operation and maintenance costs for them. If households adopt an energy-saving behavior by filling up loads (or using "half-load" settings) and avoiding peak hours (when the electricity often comes from less clean energy sources), a lower energy consumption could also reduce climate impact. On the other hand, if awareness or price signals aren't strong enough, a shift to in-unit appliances may result in an increased demand for laundry and higher energy consumption. Policy makers, developers and/or property owners can try to encourage energy saving behavior by informing households about laundry related energy-saving measures.

One limitation of our study is that we have made simplifications to enable comparison. For example, we never considered a drying cabinet. This piece of high energy-consuming equipment is common in Swedish communal laundry rooms but rare as an in-unit piece of equipment. If available, a drying cabinet could make the communal laundry room energy consumption even higher, why we argue that our calculations capture the main tendencies related to technology and behavior. On the other hand, communal laundry facilities might offer better opportunities to hang-dry laundry, which could have the opposite effect.

Our study has awoken several questions for future research. One issue is whether the observed shift in construction choice also will include rental multi-family buildings. Most multi-family buildings constructed by or for rental housing firms are still designed with only a communal laundry room, but anecdotal evidence suggests that there is a tendency to provide also rental units with laundry appliances. How common are in-unit appliances in rental housing, and do they replace or supplement communal laundry rooms? Furthermore, energy consumption during the usage phase is not the only aspect influenced by changes in construction practices. Our analysis could also be extended to include the life cycle of resources in the production of the appliances and other inputs (e.g., water and detergent) used, from the assembly stage to disposition.

As far as energy performance and laundry behavior are concerned, it would be interesting to study the possible agency problem related to life cycle cost and what appliances are chosen. It would also be 
very interesting to see if the change in building practices does in fact influence demand for laundry. Will the impact of the assumed increased convenience or the additional cost be higher? As Davis [16] points out, the impact on demand for laundry of a change in facilities would ideally be studied by randomly assigning the facilities to households and control for household and other characteristics, or at least, as in the study by Davis, control for endogeneity by considering previous washing habits. Unfortunately, as far as we are aware there is no data available to support either of these approaches.

Finally, in this study we have focused on how a shift in building practices may influence energy consumption but many perspectives are possible. One of these is how cash flows change and how they are allocated over time and between relevant actors. In tenant-owned housing, do developers save on construction costs by replacing communal laundry rooms with in-unit appliances? What is the alterative cost for the communal laundry room space? What is the value of in-unit appliances and do total revenues increase by being able to offer in-unit appliances? Do households loose or benefit financially from having in-unit appliances and how is life cycle costs impacted by choosing more efficient appliances? Especially interesting are the cases in which developers install a communal laundry room despite installing in-unit appliances, since, in those cases, residents pay for double access. In rental housing, in addition to the examples of in-unit appliances, housing firms have increasingly started to charge tenants per laundry slot instead of including a standard flat rate charge in the rent. In this way, incentives are created for tenants to reduce their laundering, without individualizing it. Based on this observation, it would be interesting to study how the life cycle costs for operation and maintenance are spread out and allocated for housing firms and tenants with communal and/or in-unit appliances.

\section{Acknowledgments}

The authors would like to thank Hans Lind, Jonas Anund and the anonymous reviewers for valuable input and comments.

\section{Author Contributions}

Lena Borg conducted the on-site collection of data. The authors equally contributed to the design of study, analysis of data and writing the paper. Both authors read and approved the final manuscript.

\section{Conflicts of Interest}

The authors declare no conflict of interest.

\section{References}

1. Directive 2009/125/EC of the European Parliament and of the Council of 21 October 2009 Establishing a Framework for the Setting of Ecodesign Requirements for Energy-Related Products. Available online: http://eur-lex.europa.eu/LexUriServ/LexUriServ.do?uri= OJ:L:2009:285:0010:0035:en:PDF (accessed on 14 February 2014). 
2. Borg, L.; Song, H.-S. Quality Change and Implications for Productivity Development: Housing Construction in Sweden 1990-2010; Working Paper Series, WP201318; Department of Real Estate and Construction Management \& Center for Banking and Finance (CEFIN), KTH Royal Institute of Technology: Stockholm, Sweden, 2013.

3. Karlsson, K.; Widén, J. Hushållens elanvändningsmönster identifierade $i$ vardagens aktiviteter; Working Paper 330; Department of Thematic Studies-Technology and Social Change, Linköping University: Linköping, Sweden, 2008. (In Swedish)

4. Mont, O.; Plepys, A. System Perspective on Service Provision: A case of Community-based washing centers for households. Int. J. Public Aff. 2007, 3, 130-151.

5. Lund, K. Tvättstugan-En Svensk historia; Nordiska Museets Förlag: Stockholm, Sweden, 2009. (In Swedish)

6. Mont, O. Institutionalisation of sustainable consumption patterns based on shared use. Ecol. Econ. 2004, 50, 135-153.

7. Energimyndigheten. Test of Semi-Professional Washing Machines, Results from the Swedish Energy Agency's Testing Lab. Available online: http://www.energimyndigheten.se/sv/Hushall/ Testerresultat/Testresultat/Fastighetstvattmaskiner/?tab=3 (accessed on 25 November 2013).

8. Energimyndigheten. Test of Semi-Professional Tumble-Dryers, Results from the Swedish Energy Agency's Testing Lab. Available online: http://www.energimyndigheten.se/sv/Hushall/ Testerresultat/Testresultat/Fastighetstorktumlare/?tab=3 (accessed on 25 November 2013).

9. BeBo. Värmedrivna vitvaror- Ett energieffektivt alternativ. Available online: http://www.bebostad.se/ documents/Projekt/Varmedrivna_viitvaror/Sammanstallning_varmedrivna_vitvaror.pdf (accessed on 25 November 2013). (In Swedish)

10. Statistics Sweden, 2012. Statistical Report; Construction: New Construction- Completed Residential Buildings 2012. Statistical Messages BO 20 SM 1301. Available online: http://www.scb.se/ Statistik/BO/BO0101/2012A01/BO0101_2012A01_SM_BO20SM1301.pdf (accessed 15 July 2013). (In Swedish)

11. Boverket. Building Regulations BBR19. Available online: http://www.boverket.se/Om-Boverket/ Webbokhandel/Publikationer/2008/Building-Regulations-BBR/ (accessed on 15 June 2013).

12. Styrelseguiden. Spara energi i Tvättstugan. [Energy Saving in the Laundry Room]. Available online: http://www.styrelseguiden.se/artiklar/Spara_energi_i_tvaettstugan-6 (accessed on 25 November 2013). (In Swedish)

13. Lindén, A.-L. Hushållsel: energieffektivisering $i$ vardagen; Research Report; Department of Sociology, Lund University: Lund, Sweden, 2008. (In Swedish)

14. Zimmerman, J.P. End-Use Metering Campaign in 400 Households in Sweden. Assessment of the Potential Electricity Savings; Contract 17-05-2743 for Swedish Energy Agency; Enertech: Félines sur Rimandoule, France, September 2009.

15. Elforsk. Visualisering av elanvändning $i$ flerbostadshus; Slutrapport inom ELAN Etapp III, Elforsk rapport 09:38; Elforsk: Stockholm, Sweden, 2009. (In Swedish)

16. Davis, L.W. Durable goods and residential demand for energy and water: Evidence from a field trial. RAND J. Econ. 2008, 39, 530-546.

17. Statistics Sweden. Living Conditions, Report No. 117: Housing and Living Environment 2006-07; Statistics Sweden: Stockholm, Sweden, 2009. 
18. Van Holsteijn en Kemna B.V., Vlaamse Instelling voor Technologisch Onderzoek NV, Viegand Maagøe A/S, Wuppertal Institut für Klima, Umwelt, Energie GmbH, 2014. “Omnibus” Review Study on Cold Appliances, Washing Machines, Dishwashers, Washer-Driers, Lighting, Set-top Boxes and Pumps FINAL REPORT. Prepared for the European Commission, DG ENER-C3 Under Specific Contract No. ENER/C3/2012-418 LOT2/03/SI2.654805 and Implementing Framework Contract No.: ENER/C3/2012-418-LOT2. Available online: http:/www.ebpg.bam.de/ de/ebpg_medien/all/omnibus_studyf_2014-03.pdf(accessed on 2 June 2014).

19. European Commission, 2012. Commission Staff Working Document "Impact Assessment". Accompanying the Document Commission Regulation Implementing Directive 2009/125/EC of the European Parliament and of the Council with Regard to Ecodesign Requirements for Household Tumble Driers. SWD(2012) 289. Available online http:/ec.europa.eu/energy/ efficiency/ecodesign/doc/td_impact_assessment.pdf (accessed on 2 June 2014).

20. Henriksson, G. Hållbart vardagsliv—mer eller mindre energikrävande konsumtion. TRITA-INFRA-FMS 2004:01. Licentiate Thesis, Lund University, Lund, Sweden, 2004. (In Swedish)

21. Shove, E. Converging Conventions of Comfort, Cleanliness and Convenience. J. Consum. Policy 2003, 26, 395-418.

22. EERE. Energy Conservation Program: Energy Conservation Standards for Residential Clothes Washers. Title 10 Code of Federal Regulations, Pt. 429 and 430. 2012 ed. US Department of Energy. Available online: http://www1.eere.energy.gov/buildings/appliance_standards/pdfs/ rcw_direct_final_rule_5_14_2012.pdf (accessed on 14 February 2014).

23. Stamminger, R. Preparatory Studies for Eco-design Requirements of EuPs (Tender TREN/D1/ 40-2005) LOT 14: Domestic washing machines and dishwashers. Part I- present situation Task 3: Economic and market analysis rev.1.0. Available online: http:/www.eup-network.de/fileadmin/ user_upload/Task_3_Economic_and_Market_Analysis_Consumer_Behaviors.pdf?PHPSESSID= 4c8f029f403a48454d21d7282c50f015 (accessed on 14 February 2014).

24. PriceWaterhouseCoopers, 2009. Ecodesign of Laundry Dryers. Preparatory studies for Ecodesign requirements of Energy-using-Products (EuP) — Lot 16. Final Report. (Contract TREN/D3/390-2006/ Lot 16/S07.77062). Available online: https://www.energimyndigheten.se/Global/F\%C3\%B6retag/ Ekodesign/Produktgrupper/Torktumlare/EuP_Laundry_Dryer_final_report_2009-04-06.pdf (accessed on 14 February 2014).

25. EERE, 2013. Energy Conservation Program: Test Procedures for Residential Clothes Dryers; Final Rule, 78 Federal Register, 157 (14 August 2013), pp. 49608-49651. US Department of Energy. Available online: https://www.federalregister.gov/articles/2013/08/14/2013-18931/energyconservation-program-test-procedures-for-residential-clothes-dryers (accessed on 14 February 2014).

26. Carlsson-Kanyama, A.; Linden, A.-L.; Eriksson, B. Residential energy behavior: Does generation matter? Int. J. Consum. Stud. 2005, 29, 239-253.

27. Carlsson-Kanyama, A.; Lindén, A-L. Energy efficiency in residences-Challenges for women and men in the North. Energy Policy 2007, 35, 2163-2172.

28. Gram-Hanssen, K. Domestic electricity consumption - Consumers and appliances. In Proceedings of the 6th Nordic Conference on Environmental Social Sciences (NESS), Turku/Åbo, Finland, 12-14 June 2003. 
29. Topten International Group. Selection Criteria Washing Machines. Available online: http://www.topten.eu/english/criteria/washing-machines-2.html\&fromid= (accessed on 3 April 2013).

30. Rüdenauer, I.; Gensch, C-O.; Quack, D. Eco-Efficiency Analysis of Washing Machines-Life-Cycle Assessment and Determination of Optimal Life Span; Report Commissioned by Electrolux-AEG Hausgeräte $\mathrm{GmbH}$ and BSH Bosch und Siemens Hausgeräte GmbH; Öko-Institut e.V. Institute for applied Ecology: Freiburg im Breisgau, Germany, 2005.

31. Davis, L.W. Evaluating the Slow Adoption of Energy Efficient Investments: Are Renters Less Likely to Have Energy Efficient Appliances? NBER Working Paper Series, w16114; National Bureau of Economic Research: Cambridge, MA, USA, 2010.

32. Gillingham, K.; Harding, M.; Rapson, D. Split Incentives in Residential Energy Consumption; Working Paper; Stanford University: Stanford, CA, USA, 2010.

33. Statistics Sweden. Yearbook of Housing and Building Statistics 2012; Statistics Sweden: Stockholm, Sweden, 2012. (In Swedish)

34. Energimyndigheten. Hushåll och energibeteende; En rapport om energi och miljömål. ER 2007:19. Underlagsrapport till ET2007:21 Energi som miljömål; Energimyndigheten: Eskilstuna, Sweden, 2007. (In Swedish)

35. SABO. Effekten av Boverkets Byggnormer på byggkostnaderna 1995-2011; SABO: Stockholm, Sweden, 2011. (In Swedish)

36. Energimyndigheten. Effektiv energianvändning. En analys av utvecklingen 1970-1998; ER 22:2000; Energimyndigheten: Eskilstuna, Sweden. (In Swedish)

(C) 2014 by the authors; licensee MDPI, Basel, Switzerland. This article is an open access article distributed under the terms and conditions of the Creative Commons Attribution license (http://creativecommons.org/licenses/by/3.0/). 